\title{
Postmortem and ex vivo carbon monoxide ventilation reduces injury in rat lungs transplanted from non-heart-beating donors
}

\author{
Boming Dong, MD, PhD, ${ }^{a}$ Paul W. Stewart, $\mathrm{PhD},{ }^{\mathrm{b}}$ and Thomas M. Egan, MD, MSc ${ }^{\mathrm{a}}$
}

Objective: We sought to determine whether ventilation of lungs after death in non-heart-beating donors with carbon monoxide during warm ischemia and ex vivo lung perfusion and after transplant would reduce ischemia-reperfusion injury and improve lung function.

\begin{abstract}
Methods: One hour after death, Sprague-Dawley rats were ventilated for another hour with $60 \%$ oxygen (control group) or $500 \mathrm{ppm}$ carbon monoxide in $60 \%$ oxygen (CO-vent group; $\mathrm{n}=6 /$ group). Then, lungs were flushed with $20 \mathrm{~mL}$ cold Perfadex, stored cold for 1 hour, then warmed to $37^{\circ} \mathrm{C}$ in an ex vivo lung perfusion circuit perfused with Steen solution. At $37^{\circ} \mathrm{C}$, lungs were ventilated for 15 minutes with alveolar gas with or without $500 \mathrm{ppm}$ carbon monoxide, then perfusion-cooled to $20^{\circ} \mathrm{C}$, flushed with cold Perfadex and stored cold for 2 hours. The left lung was transplanted using a modified cuff technique. Recipients were ventilated with $60 \%$ oxygen with or without carbon monoxide. One hour after transplant, we measured blood gases from the left pulmonary vein and aorta, and wet-to-dry ratio of both lungs. The RNA and protein extracted from graft lungs underwent real-time polymerase chain reaction and Western blotting, and measurement of cyclic guanosine monophosphate by enzyme-linked immunosorbent assay.
\end{abstract}

Results: Carbon monoxide ventilation begun 1 hour after death reduced wet/dry ratio after ex vivo lung perfusion. After transplantation, the carbon monoxide-ventilation group had better oxygenation; higher levels of tissue cyclic guanosine monophosphate, heme oxidase- 1 expression, and p38 phosphorylation; reduced c-Jun $\mathrm{N}$-terminal kinase phosphorylation; and reduced expression of interleukin- 6 and interleukin- $1 \beta$ messenger RNA.

Conclusions: Administration of carbon monoxide to the deceased donor and non-heart-beating donor lungs reduces ischemia-reperfusion injury in rat lungs transplanted from non-heart-beating donors. Therapy to the deceased donor via the airway may improve post-transplant lung function. ( $\mathrm{J}$ Thorac Cardiovasc Surg 2013;146:429-36)

\section{Supplemental material is available online.}

Lung disease is the third most common cause of death in the United States. Lung transplantation (LTX) successfully palliates patients with end-stage lung disease. However, in 2011, only 1800 lung transplants were performed in the

\footnotetext{
From the Division of Cardiothoracic Surgery, ${ }^{a}$ Department of Surgery, School of Medicine, and the Department of Biostatistics, ${ }^{\mathrm{b}}$ Gillings School of Global Public Health, University of North Carolina at Chapel Hill, Chapel Hill, NC.

This work was supported by a Cystic Fibrosis Foundation grant (EGAN06P0) and the University of North Carolina Lung Transplant Research Fund with contributions from the Doherty and Ferguson families. The UNC Department of Surgery supported the work of Dr Egan. Scanlan Instruments donated many of the microsurgical instruments.

Disclosures: Authors have nothing to disclose with regard to commercial support.

Received for publication Aug 30, 2012; revisions received Oct 17, 2012; accepted for publication Nov 6, 2012; available ahead of print Dec 26, 2012.

Address for reprints: Thomas M. Egan, MD, MSc, Division of Cardiothoracic Surgery, University of North Carolina at Chapel Hill, 3040 Burnett-Womack Building, CB \#7065, Chapel Hill, NC 27599-7065 (E-mail: ltxtme@med.unc.edu). $0022-5223 / \$ 36.00$

Copyright (C) 2013 by The American Association for Thoracic Surgery http://dx.doi.org/10.1016/j.jtcvs.2012.11.005
}

United States, and 235 patients died on the waiting list because of the critical shortage of suitable lungs from conventional organ donors. As a result of this donor shortage, strict listing criteria are espoused; many end-stage lung disease patients are not even considered candidates for transplant. We have been investigating the use of Maastricht category I non-heart-beating donors (NHBDs) as a possible solution to the lung donor shortage. ${ }^{1,2}$ These donors are individuals who die outside the hospital from cardiac arrest or as a result of trauma. Using NHBDs as lung donors would eliminate the lung shortage and allow many more patients with end-stage lung disease to undergo LTX.

Because of variable warm ischemic times and other premorbid events, lungs retrieved from NHBDs need to be assessed before transplant. Steen ${ }^{3}$ developed a method to perfuse and ventilate lungs ex vivo to evaluate lung function before transplant. We and others developed similar ex vivo lung perfusion (EVLP) circuits to evaluate human lungs retrieved from conventional donors determined unacceptable for transplantation, or lungs from donation-after-cardiac-death donors (DCDs). ${ }^{4,5}$ Steen ${ }^{6}$ used his EVLP system to evaluate lungs retrieved from conventional donors initially turned down for transplant, and successfully transplanted 6 lungs after EVLP. ${ }^{5}$ Keshavjee's group ${ }^{7}$ modified EVLP by closing 


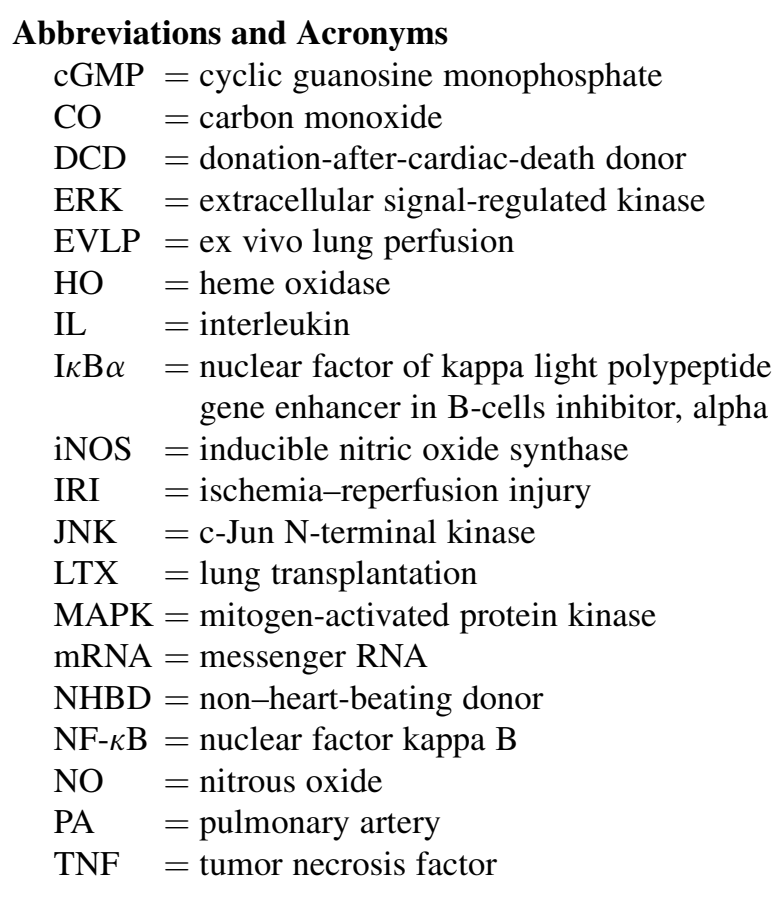

the left atrium to provide positive left atrial pressure. This enabled perfusion of human lungs ex vivo for prolonged periods. Keshavjee's group reported 20 successful LTXs after EVLP using lungs initially judged unsuitable for transplant. ${ }^{6}$

We developed a translational model of EVLP to rewarm, perfuse, and ventilate rat lungs retrieved from NHBDs before LTX. ${ }^{8}$ Using this model, we showed that administration of nitric oxide (NO) to NHBDs before and after lung retrieval reduced edema when lungs were perfused in the ex vivo circuit, reduced pulmonary vascular resistance, and improved oxygenation after transplant. ${ }^{9}$

In the current study, we show that ventilation of NHBD lungs with another gaseous second messenger, carbon monoxide (CO), after death during warm ischemia in the deceased donor, during EVLP, and postoperatively, reduces ischemia-reperfusion injury (IRI) and improves post-LTX function of lungs retrieved from NHBDs.

\section{METHODS}

\section{Donor Lung Retrieval and the Ex Vivo Circuit}

Specific details of donor lung retrieval and the rat EVLP circuit have been described. ${ }^{8,9}$ Briefly, male Sprague-Dawley rats (350-450 g) were anesthetized with intraperitoneal pentobarbital $(7.5 \mathrm{mg} / 100 \mathrm{~g}$; Abbott Laboratories, Chicago, Ill). After tracheotomy, laparotomy exposed the liver for intrahepatic injection of heparin (600 U; Elkins-Sinn, Cherry Hill, NJ). Donor rats were sacrificed with intrahepatic pentobarbital $(15 \mathrm{mg} / 100 \mathrm{~g})$. One hour after cardiac arrest, dead rats were ventilated for another hour with $60 \% \mathrm{O}_{2}$ alone (control, $\mathrm{n}=6$ ) or $500 \mathrm{ppm} \mathrm{CO}$ in $60 \%$ $\mathrm{O}_{2}(\mathrm{CO}$-vent, $\mathrm{n}=6)$ with a tidal volume of $0.75 \mathrm{~mL} / 100 \mathrm{~g}$, a rate of $70 / \mathrm{min}-$ ute, and a positive end-expiratory pressure of $3 \mathrm{~cm} \mathrm{H}_{2} \mathrm{O}$. Because of the logistics in setting up the ventilation circuit, all control donor-recipient pairs were studied before the CO-vent pairs. Assignment as donor or recipient within size-matched pairs was arbitrary. Via median sternotomy, the right ventricle was cannulated with p60 tubing and the left atrial appendage was incised to vent the pulmonary circulation. The lungs were flushed with $20 \mathrm{~mL}$ cold Perfadex (Vitrolife, Kungsbacka, Sweden) and stored at $4^{\circ} \mathrm{C}$ for 1 hour. The lung block was removed from cold storage, perfused in an ex vivo circuit with $90 \mathrm{~mL}$ Steen solution (Vitrolife) through the pulmonary artery (PA) using a Minipuls-3 peristaltic pump (Gilson Medical Electronics, Middleton, Wis). Circuit perfusate temperature was manipulated by circulating water through a Plexiglas-jacketed reservoir with a pump, positioned in a cooler containing either warm $\left(38^{\circ} \mathrm{C}\right)$ or ice-cold water. Pulmonary artery and airway pressure were monitored continuously with transducers attached to National Instruments (Austin, Tex) hardware connected to a computer with continuous real-time display. Perfusion flow rate $(3.5 \mathrm{~mL} \times$ body weight [grams]/100) was adjusted to maintain PA pressure below $20 \mathrm{~mm} \mathrm{Hg}$. When the circuit temperature reached $37^{\circ} \mathrm{C}$, the lungs were ventilated mechanically (Harvard rodent respirator model 681; Harvard Apparatus Co, Millis, Mass) with alveolar gas (5\% $\mathrm{CO}_{2}, 20 \% \mathrm{O}_{2}, 75 \% \mathrm{~N}_{2}$ ) for controls and $500 \mathrm{ppm} \mathrm{CO}$ in alveolar gas for the CO-vent group at 60 breaths/minute, with a tidal volume of $0.75 \mathrm{~mL} /$ $100 \mathrm{~g}$. Perfusate $\mathrm{pH}$ was monitored continuously with an Acumen $\mathrm{pH}$ probe (Fisher Scientific, Pittsburgh, Pa) in the venous reservoir. The $\mathrm{pH}$ was maintained near 7.40 by adding dilute $\mathrm{HCl}$ or $\mathrm{NaHCO}_{3}$ as necessary. Ventilation and perfusion continued for 15 minutes at $37^{\circ} \mathrm{C}$ to simulate ex vivo gas exchange assessment. The lungs were then perfusion-cooled to $20^{\circ} \mathrm{C}$, flushed again with cold Perfadex, and stored cold for 2.5 hours. The left lung was then transplanted. The right lung was used to evaluate postEVLP edema.

\section{Rat Lung Transplantation Technique}

Left LTX was performed using a modified cuff technique. ${ }^{8,9}$ After EVLP, the right bronchus was ligated and the trachea was retrieved with the left lung so the left lung could be ventilated separately after transplant. The transplanted left lung and the recipient's right lung were then both ventilated with $60 \% \mathrm{O}_{2}$ with or without $\mathrm{CO}$. Transonic Systems (Ithaca, NY) flow probes were placed on the left and main PAs before sacrifice 1 hour after transplant.

\section{Outcome Measures}

Outcomes were evaluated as described previously. ${ }^{8}$ Lung function was assessed by a wet-to-dry weight ratio, measured arterial $\mathrm{pO}_{2}$ /fractional inhaled oxygen concentration, airway pressure, and left PA flow per total PA flow normalized by the donor-to-recipient weight ratio. Western blots for extracted proteins quantified nuclear factor of kappa light polypeptide gene enhancer in B-cells inhibitor, alpha ( $\mathrm{I} \kappa \mathrm{B} \alpha)$ concentration and phosphorylation of 3 mitogen-activated protein kinases (MAPK): p38, c-Jun $\mathrm{N}$-terminal kinase (JNK), and extracellular signal-regulated kinase (ERK). I $\kappa \mathrm{B} \alpha, \mathrm{p} 38, \mathrm{JNK}$, and ERK were expressed as blot intensity (ImageJ software; National Institutes of Health, Bethesda, Md) in ratio to intensity of actin or total p38, JNK, and ERK. Lung protein extracted from normal rats and flash-frozen immediately after death was evaluated to demonstrate normal levels of $\mathrm{I} \kappa \mathrm{B} \alpha$, and MAPK phosphorylation in fresh lung tissue. Cyclic guanosine monophosphate (cGMP) was measured by enzyme-linked immunosorbent assay. Real-time reverse transcriptionpolymerase chain reaction quantified upregulation of lung messenger RNA (mRNA) for interleukin (IL)-6, IL-1 $\beta$, heme oxygenase-1 (HO-1), tumor necrosis factor- $\alpha$ (TNF- $\alpha$ ), intercellular adhesion molecule 1 , endothelial nitric oxide synthase, inducible nitric oxide synthase (iNOS), and B-cell lymphoma 2. Primers for reverse transcription-polymerase chain reaction are shown in online Table E1. Tissues were stained for nuclear localization of p65 component of nuclear factor kappa B (NF- $\kappa$ B). Outcomes were evaluated before and after EVLP, 1 hour after LTX, and in fresh lung tissue obtained from 6 control donors immediately after sacrifice. 


\section{Statistical Analyses}

The primary analyses relied on graphical methods and analysis of variance for paired and nonpaired responses. For 17 interval-scale outcomes, estimates of mean response \pm 1 standard error are shown. Statistical tests of the primary null hypothesis-treatment effect is 0 -were performed without multiple-comparisons adjustment. For balanced comparisons (eg, $\mathrm{n}=6$ controls, $\mathrm{n}=6 \mathrm{CO}$-vent) pooled-variance $t$ tests of size $\alpha=0.05$ were used; otherwise, the Satterthwaite $t$ test was used. Supportive analyses explored robustness of the results to statistical methods (eg, analysis of median IL-6 vs analysis of mean IL-6). All computations were performed using SAS 9.2 software (SAS Institute, Cary, NC).

\section{Animal Care}

The University of North Carolina Institutional Animal Care and Use Committee approved the protocol for this study. All animals received humane care in accordance with the Guide for the Care and Use of Laboratory Animals. ${ }^{10}$

\section{RESULTS}

\section{Lung Function}

After EVLP, CO-ventilated lungs from NHBDs developed less edema $(P=.0356)$ than lungs ventilated with $\mathrm{O}_{2}$; however, 1 hour after transplant the difference was negligible (Figure 1, A). The CO-vent treatment improved left pulmonary vein oxygenation 1 hour after transplant $(P=.0058)$, but a treatment effect was not detected $(P=.61)$ for aorta oxygenation (Figure $1, B)$. Effects of CO-vent treatment were not detected $(P=.65)$ for the left:main PA flow ratio (Figure 1, $C$ ) and for graft airway pressure $(P=.14)$.

\section{Cyclic Guanosine Monophosphate}

Mean cGMP 1 hour after LTX in graft lungs was higher in the CO-vent group $(P=.0358)$ (Figure 2$)$, whereas a treatment effect was not detected in recipients' right lungs ( $P=.22, \mathrm{n}=6$ CO-vent, $\mathrm{n}=5$ controls) (not shown).

\section{Immunoblotting for $\mathbf{I} \kappa \boldsymbol{B} \alpha$ and Mitogen-Activated Protein Kinases}

Protein from 1 animal in the CO-vent transplant group had degraded and was excluded. I $\kappa \mathrm{B} \alpha$ degradation after transplant occurred in both groups (Figure 3, A), but was reduced by $\mathrm{CO}$-vent treatment $(P=.0098)$. However, p65 localization to the nucleus by immunostaining was increased to the same extent in both groups (not shown).

All three MAPKs were activated 1 hour after LTX in both groups (Figure 3, $B-D$ ). Activation of $\mathrm{p} 38$ (Figure $3, B$ ) was higher in CO-vent animals $(P=.0032)$. c-Jun $\mathrm{N}$-terminal kinase phosphorylation (Figure $3, C$ ) was reduced in the CO-vent group $(\mathrm{n}=5)$ compared with controls $(\mathrm{n}=5$; $P=$.0077). Extracellular signal-regulated kinase phosphorylation (Figure $3, D$ ) occurred after LTX with a negligible difference in treatment group means $(P=.80)$. Each blot image shown is representative of 5 or 6 independent blots.

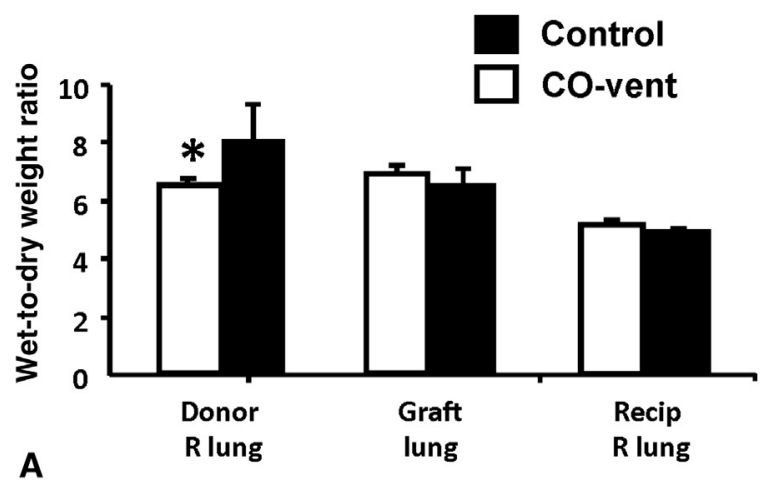

B
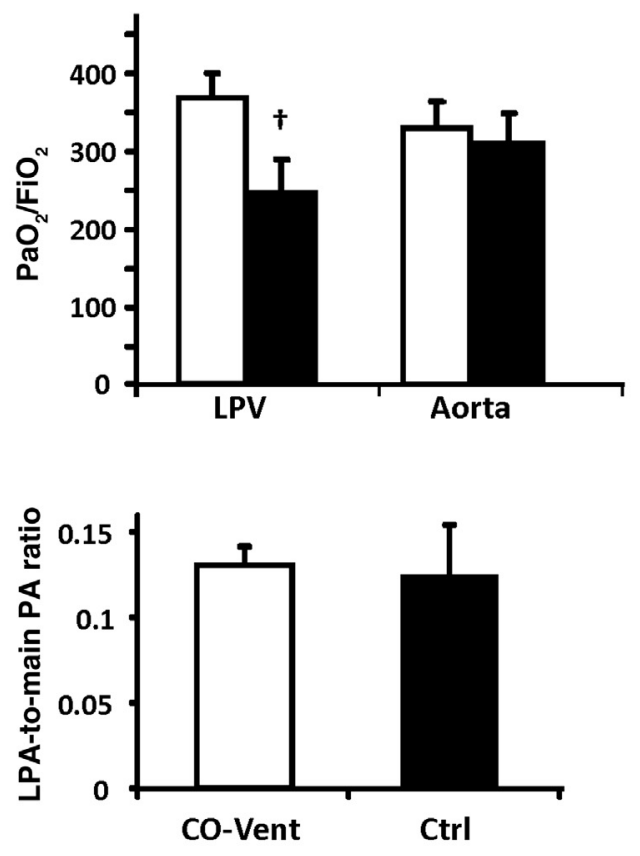

FIGURE 1. Effect of carbon monoxide $(\mathrm{CO})$ ventilation on pulmonary function. A, After perfusion in the circuit, donor lungs ventilated with $500 \mathrm{ppm} \mathrm{CO} / 60 \%$ oxygen (CO-vent) developed less edema than controls $(C t r l)$, which were ventilated with $60 \%$ oxygen $(* P=.036)$. One hour after lung transplant, the mean wet-to-dry weight ratio was similar in CO-vent and control lungs. B, After transplant, oxygenation in CO-ventilated graft lungs was better than in control lungs $(\dagger P=.0058)$. C, Flow to the graft lung (L) expressed as a ratio to total flow [LPA $=($ LPA flow rate/donor weight $) /$ (PA flow rate/recipient weight)] was similar in the 2 groups $(P=.14)$. The mean \pm 1 standard error is shown for control lungs $(\mathrm{n}=6)$ and $\mathrm{CO}$-vent $(\mathrm{n}=6)$. R, Right; Recip, recipient; $\mathrm{PaO}_{2} / \mathrm{FiO}_{2}$, measured arterial $\mathrm{pO}_{2} /$ fractional inhaled oxygen concentration; $L P V$, left pulmonary vein; $L P A$, left pulmonary artery; $P A$, pulmonary artery.

\section{Real-Time Reverse Transcription-Polymerase Chain Reaction}

One hour after LTX, HO-1 expression (Figure 4, $A$ ) was upregulated in both groups, much more so in the $\mathrm{CO}$-vent group $(P=.0314)$. Post-LTX IL-6 expression (Figure $4, B)$ in the CO-vent group $(\mathrm{n}=5)$ was less $(P=.0192)$ compared with the control group $(\mathrm{n}=5$ ). Similarly, for IL-1 $\beta$ (Figure $4, C$ ), 


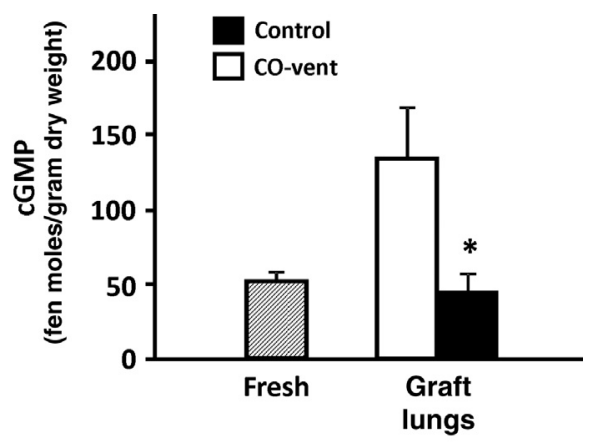

FIGURE 2. Lung tissue cyclic guanosine monophosphate ( $c G M P)$. Mean cGMP levels in transplanted lungs was increased in the carbon monoxideventilated $(C O$-vent $)$ group 1 hour after lung transplantation $(* P=.0358)$. The mean \pm 1 standard error is shown for controls $(n=5)$ and CO-vent $(n=6)$.

a treatment effect was observed $(P=.0262)$. The effect of $\mathrm{CO}$ ventilation on post-LTX TNF- $\alpha$ expression (Figure $4, D$ ) did not differ significantly $(P=.087)$. Intercellular adhesion molecule 1 transcription (Figure 4,E) increased in both groups compared with fresh lung tissue, but a $\mathrm{CO}$ ventilation treatment effect was not evident $(P=.99)$. Similarly, a treatment effect was not detected $(P=.75)$ for endothelial nitric oxide synthase transcription (Figure 4, $F$ ), iNOS transcription (not shown), and B-cell lymphoma 2 (not shown).

\section{Exploratory Results}

Figure 5 shows a relationship between $\log _{10}$ IL- 6 and $\log _{10}$ IL- $1 \beta$ mRNA levels in posttransplant lung specimens, and the impact of $\mathrm{CO}$ ventilation. This strong correlation $\left(r^{2}=0.98\right)$ implies that the signaling mechanism(s) responsible for upregulating both cytokines is/are the same, and that the mechanism(s) is/are equally inhibited by $\mathrm{CO}$ ventilation.

\section{Robustness of Results}

For all but one of the outcomes variables, the results reported here in terms of group means were found to be robust with the use of alternative statistical methods. For example, for IL-6, the easily detected post-LTX treatment effect was statistically significant regardless of method; $P=.0192$ when comparing groups in terms of mean IL-6, whereas $P=.047$ when comparing group medians, and $P=.010$ when comparing group means on a $\log _{10}$ IL-6 scale. The exception was for cGMP; the primary result, $P=.036$ for the post-LTX treatment effect in terms of mean cGMP, may be tenuous after noting that $P=.093$ for comparison of group medians (Wilcoxon test) and $P=.130$ for comparison of means on a $\log _{10}$ cGMP scale.

\section{DISCUSSION}

During the past decade, there has been increasing awareness of the role of potentially toxic gases acting as important intracellular second messengers, specifically $\mathrm{NO}, \mathrm{CO}$, and $\mathrm{H}_{2} \mathrm{~S}$. An intriguing aspect of any of these endogenously produced gaseotransmitters is that they can also be administered exogenously as therapeutic agents directly into the lung via the airway without relying on perfusion for distribution to the organ and cells of interest. At physiologic concentrations, all 3 gases share similar biologic and pharmacologic properties. They are vasodilators and have anti-inflammatory and cytoprotective effects. ${ }^{11}$ Endogenous $\mathrm{CO}$ is a by product of heme metabolism produced by HOs. HO-2 is constitutive, whereas HO-1 is a stress response gene induced by a variety of cellular stresses. Carbon dioxide administered to the lung can be transported by hemoglobin in blood to distant sites, or can be dissolved in solutions for delivery to organs at the time of retrieval or during ex vivo perfusion. Antiinflammatory effects of $\mathrm{CO}$ include induction of HO-1, which has anti-inflammatory and antiapoptotic effects, production of cGMP, and binding to heme-containing proteins, including nicotinamide adenine dinucleotide phosphate oxidase, cytochrome p450, cytochrome c, and iNOS, affecting their activity, as reviewed elsewhere. ${ }^{11,12}$

Carbon monoxide has been studied extensively in models of transplantation. ${ }^{13}$ McCurry's group ${ }^{14}$ has studied the role of $\mathrm{CO}$ comprehensively in animal models of conventional lung transplant. This is the first demonstration of the benefit of $\mathrm{CO}$ administration to lungs in a deceased NHBD. Our observations using NHBDs and EVLP are similar to those reported by McCurry's group using a model of conventional rat lung transplant and longer exposure to $\mathrm{CO} .{ }^{14}$ Kohmoto and colleagues ${ }^{14}$ showed that exposing donors (for 18 hours) or donors and recipients ( 1 hour for donors and 24 hours for recipients) to inhaled $\mathrm{CO}(250 \mathrm{ppm})$ was associated with improved gas exchange and reduced leukocyte infiltration after LTX. McCurry's group studied mRNA at 2, 6, and 24 hours after transplant, and found reductions in inflammatory cytokines when $\mathrm{CO}$ was administered to both donor and recipients. Increased mRNA for inflammatory cytokines was only observed 2 hours after LTX, confirming that this is an early event in IRI. McCurry ${ }^{14}$ did not show NF- $\kappa$ B activation by electrophoretic mobility shift assay 2 hours after transplant, but did show reduced intercellular adhesion molecule 1 mRNA in CO-ventilated animals. Our evaluations were at different time points after LTX. Although p65 nuclear localization was similar by immunostaining 1 hour after LTX, the increased $\mathrm{I} \kappa \mathrm{B} \alpha$ in lungs ventilated with $\mathrm{CO}$ suggests NF- $\kappa \mathrm{B}$ activation was reduced in the $\mathrm{CO}$-vent group. Phosphorylation of $\mathrm{I} \kappa \mathrm{B} \alpha$ releases the nuclear subunits p65 and p50, which are transported to the nucleus, where they bind to gene promoter sequences and support transcription of a variety of inflammatory cytokines. Phosphorylated $\mathrm{I} \kappa \mathrm{B} \alpha$ is quickly ubiquinated and is therefore reduced as a marker of NF- $\kappa$ B activation. Binding of the $\mathrm{p} 65$ subunit to the nucleus may be brief and transient, but $\mathrm{I} \kappa \mathrm{B} \alpha$ degradation persists until more protein is transcribed. We 

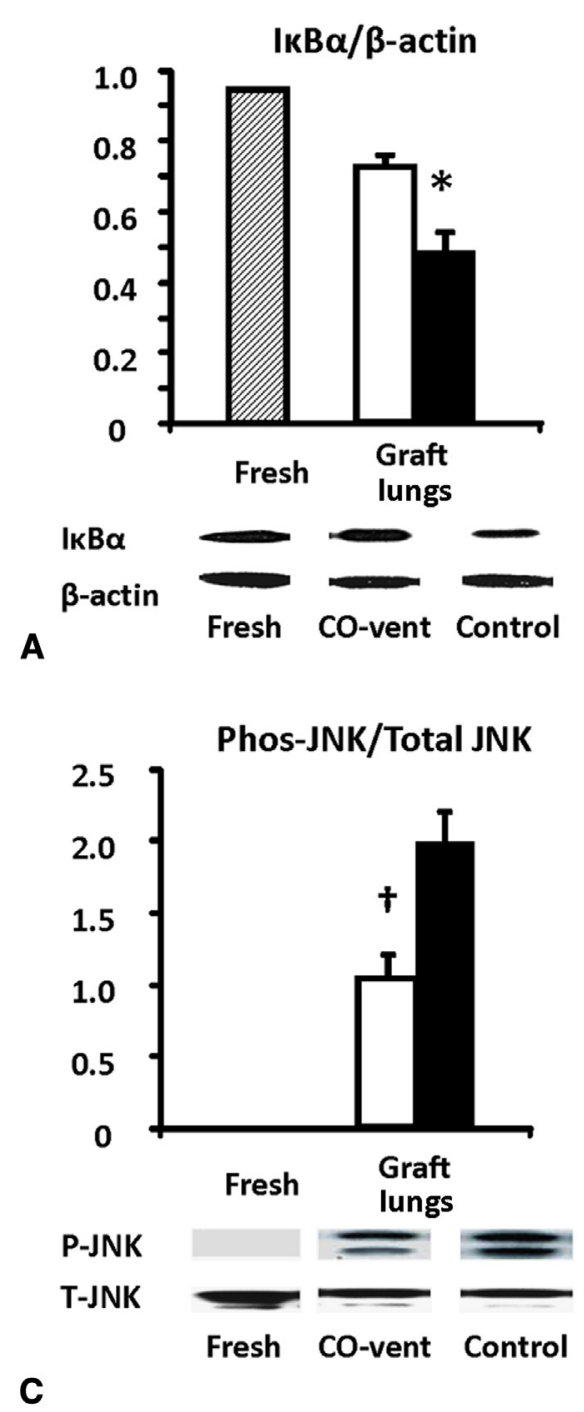

\section{Control \\ $\square$ CO-vent}
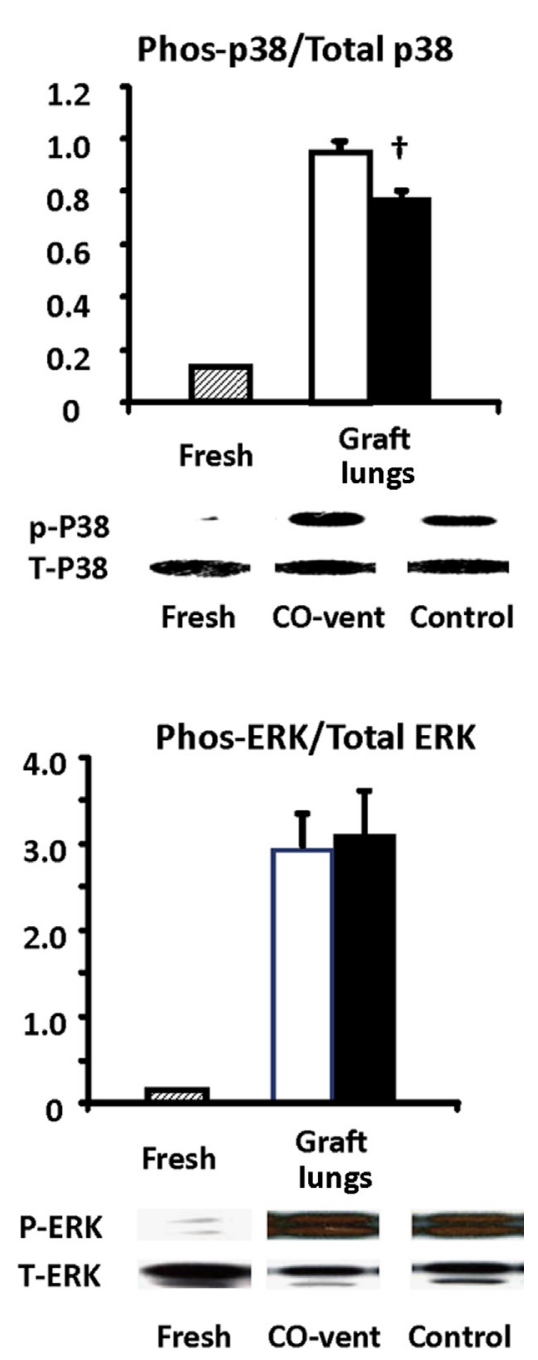

D

FIGURE 3. Western blots for nuclear factor of kappa light polypeptide gene enhancer in B-cells inhibitor, alpha $(I \kappa B \alpha)$ and mitogen-activated protein kinases $(M A P K s)$. Each graph is shown with a representative blot. A, $\mathrm{I} \kappa \mathrm{B} \alpha$ was degraded in both carbon monoxide-ventilated $(\mathrm{CO}$-vent $)(\mathrm{n}=5)$ and control $(\mathrm{n}=6)$ transplanted lungs, but less degradation was observed in the CO-vent group $\left({ }^{*} P=.0098\right) . \mathrm{B}, \mathrm{p} 38$ Activation was noted in the CO-vent $(\mathrm{n}=6)$ and control $(\mathrm{n}=5)$ groups but was more pronounced in the CO-vent group $(\dagger P=.0032)$. C, c-Jun N-terminal kinase $(J N K)$ activation was also observed in both groups ( $\mathrm{n}=5$ per group) and was reduced by the CO-vent treatment $(\dagger P=.0077)$. D, Extracellular signal-regulated kinase $(E R K)$ activation was observed in the CO-vent $(\mathrm{n}=5)$ and control $(\mathrm{n}=6)$ groups. The mean \pm 1 standard error is shown for each group.

also showed evidence of reduced transcription of RNA for some inflammatory cytokines (IL-1 $\beta$, IL-6) in the CO-vent group, consistent with reduced NF- $\kappa$ B activation.

Carbon monoxide ventilation was also associated with increased p38 activation in our study. McCurry ${ }^{14}$ showed that the protective effect of $\mathrm{CO}$ was largely abrogated by administration of a p38 inhibitor, suggesting that p38 activation may have anti-inflammatory effects. The role of p38 activation in inflammation is controversial. Administration of a p38 inhibitor prior to the onset of brain death resulted in increased elaboration of inflammatory cytokines in lung tissue. ${ }^{15}$ Like NO, CO stimulates guanylate cyclase to increase cGMP. This is likely why $\mathrm{CO}$ ventilation increased cGMP levels in transplanted lungs. Although cGMP levels increased, this was not a result of changes in iNOS or endothelial nitric oxide synthase, and appears to be an independent impact of $\mathrm{CO}$ on guanylate cyclase. $\mathrm{Cu}$ riously, this increase in cGMP did not impact pulmonary vascular resistance after LTX. Carbon monoxide ventilation did not affect left:main PA blood flow, which suggests that 

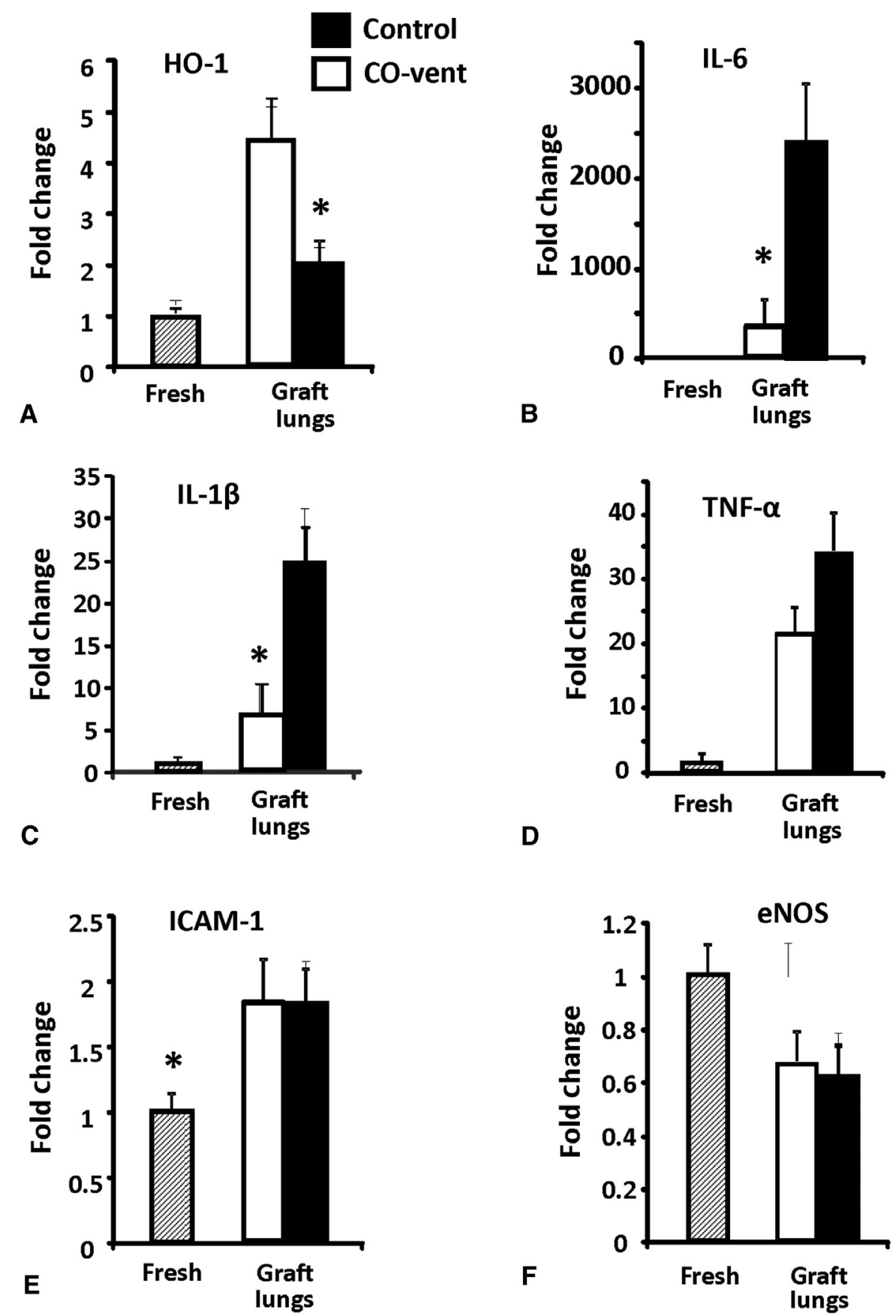

FIGURE 4. Reverse transcription-polymerase chain reaction $(R T-P C R)$ for genes indicated. One hour after transplant, carbon monoxide ventilation $(C O$ $v e n t)$ was associated with increased upregulation of heme oxygenase- $1(H O-1+)(* P=.0314)(\mathrm{A})$, decreased upregulation of IL-6 $(* P=.0192, \mathrm{n}=5$ per group) (B), and decreased upregulation of interleukin 1-beta (IL-1 $\beta)(* P=.0262, \mathrm{n}=6$ per group) (C). The 2 treatment groups were similar in regard to upregulation of tumor necrosis factor-alpha $($ TNF- $\alpha)(P=.087)(\mathrm{D})$, upregulation of intercellular adhesion molecule-1 $($ ICAM-1) $(P=.99)(\mathrm{E})$, and downregulation of endothelial nitric oxide synthase $(e N O S)(P=.75, \mathrm{n}=5 \mathrm{CO}$-vent and $\mathrm{n}=6$ controls) (F). For each of A through $\mathrm{F}$, for at least 1 of the 2 treatments, the post-lung transplant mean was statistically significantly different from the mean for fresh tissue samples.

pulmonary vascular resistance of the graft was not affected by $\mathrm{CO}$ ventilation.

In this study, we showed that $\mathrm{CO}$ administered to a Maastricht category I NHBD begun 1 hour after death, during EVLP, and for 1 hour after LTX, reduced edema formation during EVLP, and had a beneficial effect on oxygenation of the graft. The reason less edema occurred during EVLP in CO-treated lungs is unclear. As done with NO treatment of NHBDs, we subjected human pulmonary microvascular endothelial cells (HMVECs) to simulated cold IRI. Exposure of 


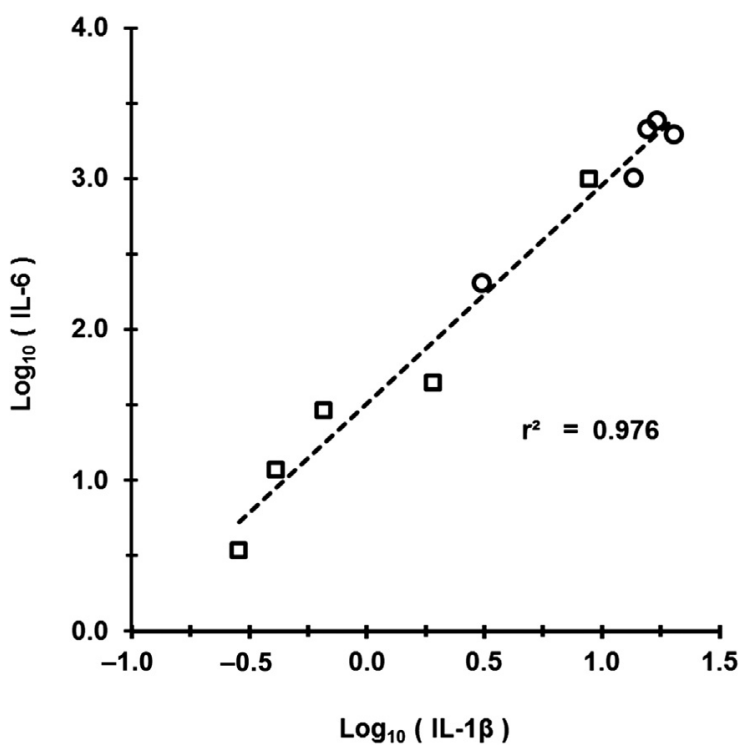

FIGURE 5. Scatter plot of log 10-transformed interleukin-6 (IL-6) and interleukin-1 beta $(I L-1 \beta)$ messenger RNA pairs from carbon monoxideventilated (squares) and control (circles) post-transplant lung samples. Near-perfect correlation $\left(r^{2}=0.98\right)$ suggests that the signaling pathway(s) responsible for upregulation of IL- 6 and IL- $1 \beta$ post-transplant are likely identical and equally inhibited by $\mathrm{CO}$-ventilation.

HMVECs to 500 ppm CO for 1 hour before exposure to cold Perfadex had no impact on inter-endothelial gap formation (results not shown). This was unlike what we observed with NO administration, in which exposure of HMVECs to $40 \mathrm{ppm}$ NO reduced inter-endothelial cell gap formation after warm cell culture media was replaced with cold Perfadex. ${ }^{9}$

We showed that HO-1 mRNA was maintained in CO-ventilated lungs, but was reduced in control lungs, suggesting that exogenous $\mathrm{CO}$ induces $\mathrm{HO}-1$ expression, or prevents downregulation. Exogenous $\mathrm{CO}$ can substitute for endogenous HO-1 in preventing hepatic IRI. ${ }^{16} \mathrm{HO}-1-$ deficient mice had much more severe injury than wild-type controls subjected to 1 hour left hilar clamp. ${ }^{17}$ Paradoxically, injury was reduced by 24-hour exposure to $0.1 \% \mathrm{CO}$ prior to ischemia. Clearly, the protective effect of $\mathrm{CO}$ was independent of HO-1 in these knockout mice. HO-1 has shown anti-apoptotic potential, probably a result of the inhibition of the pro-apoptotic c-JNK activation. ${ }^{12}$ Although we showed that $\mathrm{CO}$ ventilation reduced JNK activation, we found no difference in B-cell lymphoma 2 expression between the CO-vent and control groups, perhaps because of the short reperfusion time.

Ex vivo lung perfusion is increasingly used to evaluate lungs initially judged unsuitable for transplant. In addition to Steen's ${ }^{6}$ and Keshavjee's ${ }^{7}$ favorable experience, initial reports from Zych and colleagues ${ }^{18}$ and Aigner and colleagues ${ }^{19}$ are encouraging. Ex vivo lung perfusion was used to evaluate lungs retrieved from a category IINHBD, resulting in a successful LTX. ${ }^{19}$ Ex vivo lung perfusion may allow for safe LTX using lungs retrieved from NHBDs on a large scale. Keshavjee's group ${ }^{20}$ showed the potential to repair injured donor lungs during EVLP using gene therapy. Thus, EVLP offers an opportunity to treat lungs to reduce IRI when the organ is subsequently transplanted.

There is growing interest in expanding the donor pool by harvesting lungs from DCDs. Unfortunately, DCD lung transplant activity has increased only modestly during the past 10 years, and DCDs contribute only about $2 \%$ of all lungs transplanted in the United States. ${ }^{21}$ However, the number of Maastricht category I NHBDs is very large-in excess of 750,000 annually. Although many of these sudden deaths will be in older patients, or the lungs may be unsuitable for other reasons, if only a small fraction $(5 \%, \mathrm{n} \sim 35,000)$ of sudden death victims had lungs that could be retrieved and assessed for LTX, the impact would be enormous. Even though not all sudden cardiac arrests are attended by emergency medical services, $>300,000$ sudden deaths have cardiopulmonary resuscitation by emergency medical services. Only $7 \%$ are resuscitated successfully for transport. The median age of victims of sudden cardiac death is only 60 years old, ${ }^{22}$ so nationally there are tens of thousands of potential lung donors from this source. This represents a huge potential untapped source of lungs for transplant. The feasibility of lung transplant from NHBDs has been demonstrated in animal models by us and others, ${ }^{1,23}$ and a small experience has accumulated in humans. ${ }^{3,24} \mathrm{We}$ are beginning to evaluate lungs retrieved from category I NHBDs with EVLP (www.clinicaltrials.gov, trial no. NCT01615484). Thus, investigating strategies to improve function of lungs retrieved from NHBDs is critically important.

Because there will be an interval of time after death of a human category I NHBD before consent is obtained for lung retrieval for transplant consideration, we left the NHBD animals nonventilated for 1 hour. Human NHBDs could be ventilated during transport for lung retrieval, so there would be opportunities for therapeutic ventilation. We have shown that lung transplant from NHBDs is feasible, but can be associated with pulmonary edema and increased pulmonary vascular resistance, presumably resulting from IRI., ${ }^{2,25}$ A unique feature of lungs compared with other solid organs that are transplanted is that the airway facilitates therapeutic access to the lung to deliver pharmacologic agents, or "second-messenger" gases. In previous studies (summarized by $\operatorname{Egan}^{26}$ ), we showed that ventilating lungs after death with oxygen alone resulted in slower onset of necrosis, ultrastructural damage, maintenance of adenosine triphosphate levels, and delayed onset of increased filtration coefficient.

Ischemia-reperfusion injury is the most likely reason for primary graft dysfunction, a major cause of morbidity and the leading cause of mortality early after LTX. Lung IRI is characterized by early pulmonary edema and upregulation of cellular adhesion molecules, elaboration 
of cytokines, and an inflammatory phenotype. Primary graft dysfunction is also correlated with the risk of developing bronchiolitis obliterans syndrome. Thus, preventing or reducing IRI may have profound implications for both early function and mortality following LTX from conventional donors, as well as long-term survival after LTX from conventional donors or NHBDs.

\section{Study Limitations}

Our study has limitations. We chose to terminate our study 1 hour after LTX to interrogate lung tissue for signaling pathway activation and evidence of early gene transcription. Longer follow-up studies could determine whether the reduction in cytokine mRNA leads to less IRI. We administered $\mathrm{CO}$ at several times. Additional studies would help determine whether CO administration during EVLP alone would be beneficial. Kohmoto and colleagues ${ }^{14}$ showed administration of $\mathrm{CO}$ to conventional donors resulted in improved gas exchange, but had little impact on inflammatory cytokines after transplant. Long-term therapy of a recipient with $\mathrm{CO}$ may be impractical because $\mathrm{CO}$ binds irreversibly to hemoglobin and might eventually interfere with oxygenation. However, ventilation of lungs in an NHBD and during EVLP would likely have no detrimental effect on the recipient and might be beneficial, particularly if it reduced inflammation post-LTX by reducing NF- $\kappa \mathrm{B}$ and JNK activation. We chose to study only 1 dose of CO. Dose-response studies would be necessary prior to clinical application.

\section{CONCLUSIONS}

Our study adds to a growing body of evidence that $\mathrm{CO}$, in addition to participating as a critical second messenger, may have an important therapeutic role. This is the first study to use CO in NHBDs, which highlights the potential to use the airway in an NHBD as a therapeutic avenue.

The authors acknowledge assistance of the UNC Cystic Fibrosis Center Cell Culture Core (Scott Randell, director), which provided HMVECs; the technical assistance of John Blackwell (UNC Division of Cardiothoracic Surgery) for cell culture experiments, and Kimberlie Burns (UNC Cystic Fibrosis Center) for histology preparation; assistance with immunostaining and analysis from Nana Nikolaishvili Feinberg (UNC Translational Pathology Laboratory); and editorial assistance of Margaret Alford Cloud (UNC Division of Cardiothoracic Surgery). Vitrolife provided Perfadex and Steen solution.

\section{References}

1. Egan TM, Lambert CJ Jr, Reddick RL, Ulicny KS Jr, Keagy BA, Wilcox BR. A strategy to increase the donor pool: the use of cadaver lungs for transplantation. Ann Thorac Surg. 1991;52:1113-21.
2. Roberts CS, D'Armini AM, Egan TM. Canine double-lung transplantation with cadaver donors. J Thorac Cardiovasc Surg. 1996;112:577-83

3. Steen S, Sjoberg T, Pierre L, Liao Q, Eriksson L, Algotsson L. Transplantation of lungs from a non-heart beating donor. Lancet. 2001;357(9259):825-9.

4. Egan TM, Haithcock JA, Nicotra WA, Koukoulis G, Inokawa H, Sevala M, et al. Ex-vivo evaluation of human lungs for transplant suitability. Ann Thorac Surg. 2006;81:1205-13

5. Wierup P, Haraldsson A, Nilsson F, Pierre L, Schersten H, Silverborn M, et al. Ex vivo evaluation of nonacceptable donor lungs. Ann Thorac Surg. 2006;81:460-6.

6. Ingemansson R, Eyjolfsson A, Mared L, Pierre L, Algotsson L, Ekmehag B, et al. Clinical transplantation of initially rejected donor lungs after reconditioning ex vivo. Ann Thorac Surg. 2009;87:255-60.

7. Cypel M, Yeung JC, Liu M, Anraku M, Chen F, Karolak W, et al. Normothermic ex vivo lung perfusion in clinical lung transplantation. N Engl J Med. 2011;364: 1431-40.

8. Inokawa H, Sevala M, Funkhouser WK, Egan TM. Ex-vivo perfusion and ventilation of rat lungs from non-heart-beating donors before transplant. Ann Thorac Surg. 2006;82:1219-25

9. Dong BM, Abano JB, Egan TM. Nitric oxide ventilation of rat lungs from nonheart-beating donors improves post-transplant function. Am J Transplant. 2009; 9:2707-15.

10. National Academy of Sciences. Guide for the care and use of laboratory animals. Washington, DC: National Academies Press; 1996. Available at: http://grants. nih.gov/grants/olaw/Guide-for-the-care-and-use-of-Laboratory-animals.pdf.

11. Szabo C. Gaseotransmitters: new frontiers for translational science. Sci Transl Med. 2010;2:59ps54.

12. Ghosh S, Gal J, Marczin N. Carbon monoxide: endogenous mediator, potential diagnostic and therapeutic target. Ann Med. 2010;42:1-12.

13. Ozaki KS, Kimura S, Murase N. Use of carbon monoxide in minimizing ische$\mathrm{mia}$ /reperfusion injury in transplantation. Transplant Rev (Orlando). 2012;26: 125-39.

14. Kohmoto J, Nakao A, Stolz DB, Kaizu T, Tsung A, Ikeda A, et al. Carbon monoxide protects rat lung transplants from ischemia-reperfusion injury via a mechanism involving p38 MAPK pathway. Am J Transplant. 2007;7:2279-90.

15. Oto T, Calderone A, Li Z, Rosenfeldt FL, Pepe S. p38 Mitogen-activated protein kinase inhibition reduces inflammatory cytokines in a brain-dead transplant donor animal model. Heart Lung Circ. 2009;18:393-400.

16. Amersi F, Shen XD, Anselmo D, Melinek J, Iyer S, Southard DJ, et al. Ex vivo exposure to carbon monoxide prevents hepatic ischemia/reperfusion injury through p38 MAP kinase pathway. Hepatology. 2002;35:815-23.

17. Fujita T, Toda K, Karimova A, Yan SF, Naka Y, Yet SF, et al. Paradoxical rescue from ischemic lung injury by inhaled carbon monoxide driven by derepression of fibrinolysis. Nat Med. 2001;7:598-604.

18. Zych B, Popov AF, Stavri G, Bashford A, Bahrami T, Amrani M, et al. Early outcomes of bilateral sequential single lung transplantation after ex-vivo lung evaluation and reconditioning. J Heart Lung Transplant. 2012;31:274-81.

19. Aigner C, Slama A, Hotzenecker K, Scheed A, Urbanek B, Schmid W, et al. Clinical ex vivo lung perfusion - pushing the limits. Am J Transplant. 2012;12: 1839-47.

20. Cypel M, Liu M, Yeung J, Hirayama S, Anraku M, Sato M, et al. Functional repair of human donor lungs by IL-10 gene therapy. Sci Transl Med. 2009;1:4ra9.

21. Wigfield CH, Love RB. Donation after cardiac death lung transplantation outcomes. Curr Opin Organ Transplant. 2011;16:462-8.

22. American Heart Association. Heart disease and stroke statistics2009 update. Available at: http://www.americanheart.org/presenter.jhtml? identifier $=3037327$.

23. Steen S, Ingemansson R, Budrikis A, Bolys R, Roscher R, Sjöberg T. Successful transplantation of lungs topically cooled in the non-heart-beating donor for 6 hours. Ann Thorac Surg. 1997;63:345-51.

24. Gomez-de-Antonio D, Campo-Canaveral JL, Crowley S, Valdivia D, Cordoba M, Moradiellos J, et al. Clinical lung transplantation from uncontrolled non-heartbeating donors revisited. J Heart Lung Transplant. 2012;31:349-53.

25. Kiser A, Ciriaco P, Hoffmann S, Egan T. Lung retrieval from non-heart beating cadavers with the use of a rat lung transplant model. J Thorac Cardiovasc Surg. 2001; 122:18-23.

26. Egan T. Non-heart-beating donors in thoracic transplantation. $J$ Heart Lung Transplant. 2004;23:3-10. 
TABLE E1. Primers used in real-time reverse transcription-polymerase chain reaction

\begin{tabular}{|c|c|c|c|}
\hline Gene & Primer sequences $5^{\prime} \rightarrow \mathbf{3}^{\prime}$ & Gene accession no. & PCR product size, bp \\
\hline \multirow[t]{2}{*}{ HO-1 } & Forward: CACAAAGACCAGAGTCCCTCACAG & NM_012580 & 187 \\
\hline & Reverse: AAATTCCCACTGCCACGGT & & \\
\hline \multirow[t]{2}{*}{ IL-6 } & Forward: CAAGAGACTTCCAGCCAGTT & NM_012589 & 510 \\
\hline & Reverse: CCATTAGGAGAGCATTGGAAG & & \\
\hline \multirow[t]{2}{*}{$\mathrm{IL}-1 \beta$} & Forward: GTGGCAGCTACCTATGTCTT & M98820 & 596 \\
\hline & Reverse: GCCATCTTTAGGAAGACACG & & \\
\hline \multirow[t]{2}{*}{ TNF- $\alpha$} & Forward: GAGAAGTTCCCAAATGGGCT & NM_012675 & 203 \\
\hline & Reverse: ATCTGCTGGTACCACCAGTT & & \\
\hline \multirow[t]{2}{*}{ ICAM-1 } & Forward: GGAGATCACATTCACGGTGC & NM_012967 & 500 \\
\hline & Reverse: CACACTTCACAGTTACTTGGT & & \\
\hline \multirow[t]{2}{*}{ eNOS } & Forward: CACTGCTAGAGGTGCTGGAA & NM_021838 & 492 \\
\hline & Reverse: AGGACTTGTCCAAACACTCC & & \\
\hline \multirow[t]{2}{*}{$\beta$-actin } & Forward: CATGGATGACGATATCGCTG & NM_031144 & 408 \\
\hline & Reverse: GGATGGCTACGTACATGGCT & & \\
\hline
\end{tabular}

$\overline{P C R}$, Polymerase chain reaction; $H O-1$, heme oxygenase $1 ; I L$, interleukin; $T N F$, tumor necrosis factor; $I C A M-1$, intercellular adhesion molecule $1 ; e N O S$, endothelial nitric oxide synthase. 